\title{
Development of Professional Science Master's Degree Program in Manufac- turing Sustainability
}

\section{Dr. Ahmed H. Elsawy, Tennessee Technological University}

Dr. Ahmed ElSawy joined Tennessee Technological University (TTU) as a Professor and Chairperson, Department of Manufacturing and Engineering Technology since July 1, 1999. He holds B.Sc., M.Sc. and Ph.D. degrees in Mechanical Engineering with emphasis on Materials processing and Manufacturing engineering. Prior joining TTU. Dr. ElSawy held several industrial and academic positions in the USA and abroad. He was a professor and graduate program coordinator at the University of Northern Iowa, a founder director of manufacturing engineering program at St. Cloud State University, Project Manager at Rensselaer Polytechnic Institute, and Visiting Scholar at TU-Berlin, Germany. Dr. ElSawy teaching and research interests are in the areas of material processing, metallurgy and manufacturing systems. His current research interests are in the areas of renewable energy, bioenergy from waste in order to reduce the carbon footprint and preserve natural resources for future generations. Dr. ElSawy received $~ \$ 2 M$ of state, federal, and industrial grants in support of his laboratory development and research activities. He advised several masters and doctoral students who are holding academic and industrial positions in the USA, Germany and Taiwan. Dr. ElSawy has numerous publications in national and international conferences and refereed journals.

Dr. Fred Vondra, Tennessee Technological University

Dr. Ahmed K Kamal, Tennessee Technological University

Dr. Ahmed Kamal is an associate professor in the Department of Manufacturing and Engineering Technology since August 2008. He holds a B.Sc. in Electrical and Electronic Engineering from Cairo University, Egypt in 1969, M.Sc. Electrical Engineering in 1978 and a Ph.D. in Electrical, computer and Control Engineering from Bradford University, England in July 1981. Prior joining TTU, Dr. Kamal held several positions as Electronic Engineer in Ford Motor based in Egypt and United Kingdom. Dr. Kamal also was a non-tenure professor research professor at Biocomputing Program, Biomedical Engineering, Johns Hopkins University, Baltimore, MD, USA. Also, He was Professor of Electrical Engineering, College of Engineering King Saud University, Riyadh, Saudi Arabia. Before that he was visiting professor in the Computer and Biomedical Engineering Department, College of Engineering, Boston University. Dr. Kamal published more than 80 Papers in Peer reviewed Journals and conferences in the US and abroad in Engineering Education, Electrical Engineering and Bioengineering. 


\title{
Development of Professional Science Master's Degree Program in Manufacturing Sustainability
}

\author{
Dr. Ahmed H. Elsawy, Tennessee Technological University
}

Dr. Ahmed ElSawy joined Tennessee Technological University (TTU) as a Professor and Chairperson, Department of Manufacturing and Engineering Technology since July 1, 1999. He holds B.Sc., M.Sc. and Ph.D. degrees in Mechanical Engineering with emphasis on Materials processing and Manufacturing engineering. Prior joining TTU. Dr. EISawy held several industrial and academic positions in the USA and abroad. He was a professor and graduate program coordinator at the University of Northern lowa, a founder director of manufacturing engineering program at St. Cloud State University, Project Manager at Rensselaer Polytechnic Institute, and Visiting Scholar at TU-Berlin, Germany. Dr. ElSawy teaching and research interests are in the areas of material processing, metallurgy and manufacturing systems. His current research interests are in the areas of renewable energy, bioenergy from waste in order to reduce the carbon footprint and preserve natural resources for future generations. Dr. ElSawy received \$2M of state, federal, and industrial grants in support of his laboratory development and research activities. He advised several masters and doctoral students who are holding academic and industrial positions in the USA, Germany and Taiwan. Dr. ElSawy has numerous publications in national and international conferences and refereed journals.

Dr. Ahmed K Kamal, Tennessee Technological University

Dr. Ahmed Kamal is an associate professor in the Department of Manufacturing and Engineering Technology since August 2008. He holds a B.Sc. in Electrical and Electronic Engineering from Cairo University, Egypt in 1969, M.Sc. Electrical Engineering in 1978 and a Ph.D. in Electrical, computer and Control Engineering from Bradford University, England in July 1981. Prior joining TTU, Dr. Kamal held several positions as Electronic Engineer in Ford Motor based in Egypt and United Kingdom. Dr. Kamal also was a non-tenure professor research professor at Biocomputing Program, Biomedical Engineering, Johns Hopkins University, Baltimore, MD, USA. Also, He was Professor of Electrical Engineering, College of Engineering King Saud University, Riyadh, Saudi Arabia. Before that he was visiting professor in the Computer and Biomedical Engineering Department, College of Engineering, Boston University. Dr. Kamal published more than 80 Papers in Peer reviewed Journals and conferences in the US and abroad in Engineering Education, Electrical Engineering and Bioengineering. 


\title{
Development of Professional Science Master's Degree Program in Manufacturing Sustainability
}

\author{
Ahmed H. ElSawy*, Awni Qasaimeh, Ahmed Kamal, Fred Vondra \\ Department of Manufacturing and Engineering Technology \\ College of Engineering, Tennessee Technological University \\ Cookeville, TN 38505-0001
}

\begin{abstract}
The main purpose of the Professional Science Master's in Manufacturing Sustainability (PSM-MS) is to provide an interdisciplinary educational learning platform for greening our future by educating our current and future workforce. It is not like other master's degree in engineering or engineering technology; PSM-MS is intended for educating current professionals from the manufacturing industry to promote knowledge and competencies related to manufacturing sustainability. Its interdisciplinary technical-managerial approach includes a business background and concepts that are applicable across fields and as diverse as, environmental social policy, environmental economics, lean manufacturing and strategy for sustainability, energy management and alternative energy production.
\end{abstract}

\section{What is PSM?}

The PSM is an innovative new master's program designed to prepare students with the scientific training necessary to advance and excel in science, while simultaneously developing highly valued business skills. Programs are characterized by "science-plus" curricula, combining rigorous graduate study in science or mathematics with skills-based coursework in management, policy, or law. PSM programs emphasize the written and verbal communication skills, leadership, and team-building required in professional settings. Instead of a thesis, most PSM degrees require a collaborative research project, as well as an internship in the industrial sector. PSM graduates are equally as comfortable in the science lab as in the board room, court room, and other professional settings ${ }^{1}$. All have been developed in concert with local manufacturing employers and members of PSM-MS advisory board and are designed to dovetail into present and future professional career development.

\section{Manufacturing Sustainability Overview}

There is a strong consensus among national and global leaders that manufacturing sustainability will be an "increasingly important topic" in global competitiveness. There are many commonly shared definitions of sustainable manufacturing. The United Nations definition is: "meeting the needs of the present without compromising the ability of future generations to meet their own needs ${ }^{2}$ ". The Department of Commerce (DOC) defined manufacturing sustainability as: "Sustainable manufacturing is defined as the creation of manufactured products that use processes that minimize negative environmental impacts, conserve energy and natural resources, are safe for employees, communities, and consumers and are economically sound ${ }^{3 \%}$. The Environmental Protection Agency (EPA) definition is: "Manufacturing Sustainability is the creation of manufactured products through 
economically-sound processes that minimize negative environmental impacts while conserving energy and natural resources. Sustainable manufacturing also enhances employee, community, and product safety ${ }^{4}$ ”. So, Manufacturing Sustainability (MS) strategy could be considered developing technologies to transform resources into goods and services that respond to basic needs and improve the humans' quality of life. While being economically viable, manufacturing sustainability should also minimize the use of natural resources and toxic materials, the emission of waste and pollutants, and negative impacts to humans and the environment considered over the product life cycle. The success of manufacturers in the global market remains challenged with reducing its carbon footprint, measuring and trading emissions and developing innovative, sustainable technologies.

\section{Workforce Need}

As Manufacturing Sustainability takes hold across the country, the demand for workforces who are trained to identify opportunities for improving process efficiencies and prevent environmental wastes will considerably increase. While some job candidates have a basic knowledge of lean manufacturing techniques, few realize how environmental wastes and pollution prevention relate to lean initiatives. Based on a request from an automotive manufacturing partner, Tennessee Technological University is taking a lead in filling this knowledge gap and meeting these demands by incorporating manufacturing sustainability concepts into the classroom. Meeting manufacturing sustainability goals requires a commitment to incorporate green manufacturing knowledge in the day-to-day activities of all manufacturing professionals, not just executives, managers, or process engineers. Integrating these course materials into the proposed PSM-Manufacturing Sustainability curriculum will help build our state and country's green workforce capacity, which will help revitalize our manufacturing sector and promote job growth.

\section{Impact}

As environmental issues become more complex due to population growth, pollution, and limited natural resources, the Professional Science Master's in Manufacturing Sustainability program will effectively prepare future professionals and current manufacturing practitioners in three focus areas: Business Management, Lean Manufacturing and Pollution Prevention, and Energy and Carbon. Through this effort, Tennessee Technological University will become recognized as a leader in Manufacturing Sustainability studies in the southeastern United States.

"Sustainability will help us be a trusted partner in expanding in markets around the world. Our emphasis on resource efficiency positions us well to weather rapidly rising costs for energy and materials ${ }^{5 \%}$.

\section{— Alan Mullaly, CEO of Ford Motor Company}

\section{Curriculum}

The curriculum is made up of three modules: Environmental Sustainability, Lean

Manufacturing and Pollution Prevention, and Energy and Carbon. Topics include: Life Cycle Analysis, Full Cost Accounting, Pollution Prevention, Green Value Stream Mapping, Waste Management, Resource Conservation, Energy Efficiency, Carbon Foot-printing, Environmental Justice and Social Responsibility.

The program is designed for graduates of approved programs and who hold a baccalaureate degree in science, technology, engineering, or mathematics (STEM). Candidates not holding 
an appropriate baccalaureate degree may be required to complete necessary prerequisite courses prior to admission to the program. Thus, a baccalaureate degree is required for full standing. Applicants that have baccalaureate degrees in a closely related field will be evaluated on a case-by-case basis and may be admitted to full standing upon completion of identified background courses. Academic exceptions may be granted in exceptional circumstances for individuals with extensive professional experience or other background that, in the opinion of the admission committee, qualifies the candidate for admission.

Graduation requirements are successful completion of all course work and the capstone internship, with an overall GPA 3.0. Other graduation requirements can be found on TTU's graduate catalogue. TOTAL credits required for the program are 33 credit hours and represent the three pillars of sustainability E3: Environment, Economy, and Energy as well as the social impact:

1. Business Courses (12 credit hours): The business courses are taught online and on campus via TTU's MBA program. These courses would be available to any PSM student. The prerequisites, which are available on CD, will be met through the College of Business's modules that can be taken at the student's own pace and can be completed within a month, a week, or a weekend.)

Organizational Leadership 3 cr.hr.

Strategic Marketing 3 cr.hr.

Applied Linear Statistical Methods I 3 cr.hr.

Accounting Information for Management Decisions 3 cr.hr.

\section{Concentrations (18 credit hours):}

Environmental Social Policy

3 cr.hr.

Environmental Economics

3 cr.hr.

Lean Six Sigma Manufacturing

$3 \mathrm{cr} . \mathrm{hr}$.

Manufacturing Strategy for Sustainability

$3 \mathrm{cr} . \mathrm{hr}$.

Energy Management Principals

$3 \mathrm{cr} . \mathrm{hr}$.

Internship

3 cr.hr.

3. Electives ( 3 credit hours): Students will take one elective course in the student's area of professional interest (subject to Graduate Advisory Committee approval).

Note: The one-course elective allows students to choose a course to broaden or enhance their educational program.

Applied Environmental Chemistry

Environmental Chemistry

Environmental Management Systems

Experimental Design I

Experimental Design II

Industrial Electronics

CNC Concepts, Advanced Techniques \&Applications

Programmable Logic Controllers and Process Control

Industrial Automation and Robotics

Advanced CAD Techniques

Plant Layout and Materials Handling

Geometric Dimensioning and Tolerancing

Industrial Supervision

Rapid Prototyping
3 cr.hr.

3 cr.hr.

3 cr.hr.

3 cr.hr.

3 cr.hr.

3 cr.hr.

3 cr.hr.

3 cr.hr.

3 cr.hr.

$3 \mathrm{cr} . \mathrm{hr}$.

3 cr.hr.

3 cr.hr.

3 cr.hr.

3 cr.hr. 
Tool Design

Maintenance, Replacement and Reliability Engineering

Product Design \& Development
3 cr.hr.

$3 \mathrm{cr} . \mathrm{hr}$.

3 cr.hr.

\section{Admission Requirements}

Following are the admissions requirements:

- Undergraduate GPA of at least 3.0 on a 4.0 scale from a STEM (Science, Technology, Engineering and Mathematics) related discipline. Candidates not holding an appropriate baccalaureate degree may be required to complete necessary prerequisite courses prior to admission to the program. Thus, a baccalaureate degree is required for full standing. Applicants that have baccalaureate degrees in a closely related field will be evaluated on a case-by-case basis and may be admitted to full standing upon completion of identified background courses. Academic exceptions may be granted in exceptional circumstances for individuals with extensive professional experience or other background that, in the opinion of the admission committee, qualifies the candidate for admission.

- Total of at least 1000 on the verbal and quantitative portions of the $\mathrm{GRE}^{\circledR}$ General Test (GRE) (306 New revised score) along with a 3.5.

- Official transcripts from all previously-attended colleges or universities.

- Three (3) letters of recommendation from faculty familiar with the academic ability of the applicant.

- International applicants must also meet the English Language Requirement by providing test results on one of the following: (1) TOEFL 550 minimum (213 computer-based or 79 internet-based) or (2) IELTS minimum base score of 5.5.

\section{Exit Requirements}

Following the completion of the program of study, including the thesis or final research paper, the student will present the final research paper, open to the public, to the graduate committee for critique and must pass a final oral examination administered by the graduate committee.

\section{Plans for Accreditation}

The College of Engineering plans to seek recognition of the Professional Science Master's in Manufacturing Sustainability degree through the Council of Graduate Schools (CGS) as a concentration in a Professional Science Master's program at Tennessee Technological University. The Professional Science Master's is a unique professional degree grounded in natural science, technology, engineering, mathematics and/or computational sciences and is designed to prepare students for direct entry into a variety of career options in industry, business, government, or nonprofit organizations. It is a distinctive advanced degree for those intending to pursue a career in the practice of science. Professional Science Master's programs prepare graduates for high-level careers in science that have a strong emphasis on such skill areas as management, policy, and entrepreneurship. A Professional Science Master's recognition provides assurance that the program conforms to nationally accepted criteria. Recognized Professional Science Master's programs agree to use the name "Professional Science Master's" and the Professional Science Master's logo on websites and other promotional materials. The following criteria must be met by Professional Science Master's programs:

1. The institution must be accredited by a regional accrediting association, or in the case of international applicants, a recognized organization or appropriate governing body that accredits or recognizes institutions of higher learning. 
2. A program must have stated goals and learning outcomes appropriate to the particular degree.

3. The total number of credits must be at least equivalent to the minimal number required for a master's degree at the institution.

4. Programs must include the following three components:

a. A majority of the course content in the natural sciences, technology, engineering, mathematics, and/or computational sciences.

b. A professional skills component must be developed in consultation with leaders from the targeted industry, business, government, or nonprofit organizations.

c. An experiential component that must include at least one capstone project, supervised collaboratively by faculty and employers, evaluated or graded by faculty, and typically developed with an employer(s), which integrates the practical application of scientific and professional knowledge, behavior, and skills. The experiential component typically includes a structured internship and provides an opportunity for students to demonstrate proficiency in written and oral communication skills.

5. Program quality assurance must be provided using the faculty-based mechanisms normally used by the institution for graduate programs in order to ensure that the program is fully integrated into the academic offerings of the institution and that it sustainable over time.

6. An active and engaged advisory board of leaders from industry, business, government, or non-profit organizations is required.

7. The program must collect annual data relative to enrollment, degrees, completion, and demographics; and the employment history of graduates should be tracked to help assess program outcomes.

Regular SACS accreditation standards will apply to the Professional Science Master's with a concentration in Manufacturing Sustainability program.

\section{Summary}

Tennessee Tech University is committed to expanding and strengthening its manufacturing engineering technology program offerings in order to provide students a complete range of programs from which to choose. The newly developed master's program would prepare students for jobs that are deemed in the national and state interest and provide Tennesseans with highly paid and rewarding career opportunities in Tennessee. This is especially true for the Professional Science Master's with concentration in Manufacturing Sustainability program. The program was approved by Tennessee Board of Regents and Tennessee Technological University is in the process of applying for the Professional Science Masters designation from the National Council of Graduate Schools. This designation will further identify the PSMMS as a career oriented degree program.

\section{References}

1. http://sciencemasters.com/ScienceMastersHome/Employers/tabid/55/Default.as px.

2. Steve Evans, The Manufacturer, "Interview with Professor Steve Evans: Making sustainable", May 3, 2013.

3. From the National Council for Advanced Manufacturing (NACFAM), http://www.nacfam.org/PolicyInitiatives/SustainableManufacturing/tabid/64/De fault.aspx. 
4. From the Department of Commerce, International Trade Administration website, http://www.trade.gov/competitiveness/sustainablemanufacturing/how_doc_defi nes_SM.asp.

5. Open Research Forum, "ASME Sustainable Manufacturing: Preparing for a New Business Perspective", Washington, DC, June 18, 2013.

6. http://ophelia.sdsu.edu:8080/ford/06-032012/microsites/sustainabilityreport201011/overview-letter-mulally.html 